\title{
Mathematical Methods in the Study of Historical Chronology
}

Florin Diacu

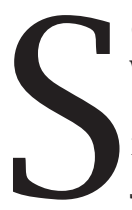

ome ancient and medieval historical dates we learn in school may stick in our minds: 1193 BC (the fall of Troy), 753 BC (the founding of Rome), $\mathrm{AD} 1$ (the birth of Jesus), or AD 1066 (the battle of Hastings), to mention just a few. Most of us take these dates for granted, but are they correct? Anatoli Fomenko, a fellow of the Russian Academy of Sciences, finds them fictitious and promotes an alternative chronology that often differs from tradition by more than a millennium [1].

The concerns about the correctness of ancient and medieval dates are not new. Isaac Newton also opposed them. In his last book, which he finished preparing for publication just before his death, he argued that ancient Greek history should be about 300 years shorter than claimed [9]. Since the global chronology is based on the Greek chronology, the foundation of its edifice appears to be shaky.

It is thus natural to ask how historical events were dated, why they are controversial, and if mathematics might play any role in raising or solving these problems. To lay the background towards throwing some light on these questions, let us first make an incursion into the origins of history's timetables. The material that follows is based on [1], the second edition of a book originally published by Knopf Canada.

\section{A Brief History of Historical Dating}

The first writer whom we know to have been interested in historical chronology is the Greek

Florin Diacu is professor of mathematics at the Pacific Institute for the Mathematical Sciences and University of Victoria. His email address is di acu@math . uvic . ca.

DOI: http://dx.doi.org/10.1090/noti962 historian Ephorus of Cyme (ca. 405-330 BC), who provided many dates in his work on universal history. His more famous predecessor Herodotus (ca. 484-425 BC) had been far less interested in placing events in time. Sextus Julius Africanus (ca. AD 160-240), often called the first true chronologist, is considered the father of biblical history, an independent field from which the science of historical dating would later borrow its principles. In his work Chronologia, he put together dates from Hebrew, Egyptian, Greek, Persian, and other sources by connecting various pieces of information, as can be noted in the example below [15]:

If one computes backwards from the end of captivity, there are 1,237 years. So, by analysis, the same period is found to be the first year of the Exodus of Israel under Moses from Egypt, as from the 55th Olympiad to Ogygus, who founded Eleusis. And from here we get a more notable beginning for Attic chronography.

The work of Julius Africanus was continued by Eusebius, Bishop of Caesarea (ca. AD 260-341), who came up with tables that compared parallel major events. For instance, he informs us that Jesus was born in the year of the 194th Greek Olympiad, which took place 2,010 years after the birth of Abraham, in the forty-second year of Augustus's reign and the twenty-eighth year after the Roman subjugation of Egypt, or the year when Antony and Cleopatra died. All of Eusebius's entries start with "the year of Abraham," i.e., 2010 BC. Unfortunately the calculations are based on the unrealistic life spans mentioned in the Bible, such as Adam, 930 years; Noah, 950 years; Abraham, 
175 years; or Moses 120 years, numbers upon which later chronologists built history.

Among the medieval researchers who followed this tradition were Martin Luther and Gerardus Mercator. But in spite of their contributions, chronology remained a gathering of disparate dates used mainly for religious purposes, such as making sense of the biblical stories or deciding Easter Day. The current consensus among researchers, as expressed by Denys Hay, a professor at the University of Edinburgh, is that "[i]n classical antiquity there was virtually no system of chronology available to historians" [7].

The breakthrough came in 1583, when the French scholar Joseph Justus Scaliger published a sevenvolume work titled De Emendatione Temporum, which provided dates for the main historical events of humankind. This colossal enterprise treats in detail the astronomical bases of more than fifty calendars. To achieve this feat, Scaliger had taught himself thirteen languages, Hebrew and Arabic among them, becoming one of the most respected philologists of his time. He embarked on his chronology work aiming to understand the flow of ideas and who had influenced whom in ancient literature. He ended up sorting out the problems of history, an achievement for which he received in 1593 a research professorship at the University of Leiden, where he worked until his death in 1609. His second and last treatise was Thesaurus Temporum, a collection and arrangement of all available ancient chronological sources.

Despite their deficiencies, his historical timetables survived and were later used to build all Eastern chronologies, including those of India, China, and Japan. Anthony Grafton, Professor of European History at Princeton University, remarked recently that "[t]he few modern historians who mentioned Scaliger described him as a brilliant innovator who created a discipline in the teeth of ferocious opposition" [6]. No doubt, this was the new science on which history would rest.

\section{Early Use of Mathematics}

Apart from simple arithmetic operations aimed at understanding various calendars, the early use of mathematics in chronology was mostly reduced to the computation of eclipses. Scaliger based his method on the astronomical and calendrical information he gathered from ancient sources, aiming to fix some historical landmarks, which he could then connect to other events. Since total solar eclipses, for instance, could be computed with reasonable accuracy, he interpreted the ancient descriptions of such celestial phenomena to place them in time.

Scaliger also intuitively applied congruences and the Chinese Remainder Theorem to fix the
Julian epoch to noon on Monday, January 1, 4713 $\mathrm{BC}$, which thus became a convenient reference point for all his computations [13]. A method he then devised, based on the twelfth-century work of Roger of Hereford and used extensively by Scaliger's follower Dionysius Petavius, was that of combined cycles. This method employs the numbers 19, 28, and 15 in terms of congruences: 19 stays for the lunar cycle, i.e., the number of integer years the moon takes to complete an integer number of orbits (235) around Earth; 28 stays for the solar cycle, i.e., the minimum number of years after which the Gregorian calendar repeats itself; and 15 stays for the Roman indiction, a taxation cycle established in AD 313 and used as late as the sixteenth century in some places. This method assigns to each date in history its Julian count (the number of years since the Julian epoch). Every Julian count up to 7980 has a unique triplet of numbers resulting from the remainder obtained when dividing the Julian count by 19, 28, and 15 . So if a certain event can be associated with the lunar cycle, the solar cycle, and the Roman indiction, its year can be determined.

But Scaliger's most important contributions are with understanding calendars, most of which were long forgotten during his time. Such studies are multidisciplinary. To reach the point when mathematics can be of any use, he had to first unravel the calendar's language and the deeper meaning of the nomenclature. Scaliger started almost from scratch. An example of the difficulties he encountered are made evident in the lines he wrote in 1568 prompted by some third century AD statements he disagreed with [5]:

I do not see how the month of April can derive its name from aperio [to open, to discover]. First of all, since the year initially had only ten months, they must have always wandered and had no fixed position in the year.... [In fact] aprilis comes from aper, which is boar.

Once the calendrical language was clear, many other difficulties occurred. The rules of the old Roman (pre-Julian) calendars, for instance, often changed according to the interests of the political leaders. These alterations are not only hard to trace but are also detrimental in chronology studies because they can lead to misinterpretations that may give rise to large errors in time. Apart from such subjective issues, another problem Scaliger had to deal with was the type of calendar he tried to decipher: lunar, solar, lunisolar, or of some arbitrary type, most of which required not only solid knowledge of astronomy, but some algorithmic sophistication as well. The computational difficulties are easy to overcome today, so it's no 
wonder that calendrical calculations now belong to the realm of computer science [14], but Scaliger had to approach them without proper mathematical training, thus having at his disposal only some rudimentary tools.

\section{Modern Developments}

Scaliger's work was attacked from the very beginning, but apart from being subject to fine tuning, it survived unscathed. Historians based their theories on it, and today every student of history takes it for granted. Astronomers all did their best to support it with observational and computational data, and other scholars studied the match between dates and the information that can be gathered from ancient horoscopes (more about them later).

Among the detractors of Scaliger's chronology are a few scientists and mathematicians, such as Isaac Newton and Anatoli Fomenko, but also many cranks, the most famous being Immanuel Velikovsky, who made a fortune from the books he wrote on this topic in the 1950s [1]. The latter give a bad name to anyone who opposes the traditional view, so neither Newton nor Fomenko have been free of harsh criticism. Fomenko, especially, has many opponents, who often find good ammunition against his conclusions. Nevertheless, he and his collaborators introduced new mathematical methods in the modern study of chronology. We will further present some of them, leaving it to the reader to pass judgment about their merit.

\section{The Moon's Acceleration}

Understanding the moon's orbit around Earth is a difficult mathematical problem. Isaac Newton was the first to consider it, and it took more than two centuries until the American mathematician George William Hill found a suitable framework in which to address this question. Still, the moon's orbit is not fully explained today, and Fomenko was dealing with some details at the end of the 1970s.

He was concerned with the acceleration, $D^{\prime \prime}$, of the moon's elongation, which is the angle between the moon and the sun as viewed from Earth. This acceleration $D^{\prime \prime}$ is computable from observations, and its past behavior can be determined from records of eclipses. Its values vary between -18 and +2 seconds of arc per century squared. Also, $D^{\prime \prime}$ is slightly above zero and almost constant from about 700 BC to AD 500, but it drops significantly for the next five centuries, to settle at around -18 after AD 1000. Unfortunately this variation cannot be explained from gravitation, which requires the graph to be a horizontal line.

Among the other experts in celestial mechanics who attacked this problem was Robert Newton from Johns Hopkins University. In 1979, he published the first volume of a book that considered the issue by looking at historical solar eclipses [11]. Five years later, he came up with a second volume, which approached the problem from the point of view of lunar observations. His conclusion was that the behavior of $D^{\prime \prime}$ could be explained only by factoring in some unknown forces [12].

Fomenko found the idea of unknown forces outlandish, so he used his own chronology to redate Robert Newton's astronomical records, which led to the conclusion that $D^{\prime \prime}$ was almost constant in time [2]. His result was in agreement with Newtonian gravitation, according to which the rotation of the Earth around its axis slows down when $D^{\prime \prime}$ decreases.

Robert Newton either ignored Fomenko's results or never learned about them. For the rest of his life, he continued to present evidence for the unpredictable changes of the moon's acceleration. Among the potential factors that change the values of $D^{\prime \prime}$, he suggested the Earth's magnetic force, the tidal friction between water and sea bottoms, the growth of the Earth's core, and the withdrawal of the ice caps, but he offered no computations towards proving their influence on the behavior of $D^{\prime \prime}$.

Fomenko and Newton approached the problem from opposite points of view. The former doubted the date of every eclipse, whereas the latter accepted them all, going as far as to disagree with the descriptions of the ancient observers, trusting only a few of the 370 cases he studied: "We have found too many instances of an eclipse that could not possibly have been total but that was so recorded, sometimes in a quite picturesque manner," he wrote in the second volume of his book. Fomenko, instead, trusted the word of the observers, refusing to accept the existence of mysterious forces. A closer look at the data, however, shows that Fomenko's graph after $\mathrm{AD}$ 900 is similar to Newton's. In the middle period, for which Newton found a sharp drop of $D^{\prime \prime}$, Fomenko obtained results he deemed unreliable. The most ancient period vanished, because he shifted the chronology forward in time.

So, if we ignore the period before AD 900, there is not much difference between the results of Newton and Fomenko. The change of chronology has not led to a straight line starting with antiquity but has only eliminated the data before AD 500 and cast a doubt upon the information between 500 and 900. Newton's results can be interpreted similarly: if we exclude the possibility of mysterious forces, his graph puts traditional ancient and medieval chronology in doubt. 


\section{Calendar Reform and the Council of Nicaea}

The Christian calendar has its origins in Rome. In $46 \mathrm{BC}$, Julius Caesar established the length of months at thirty or thirty-one days, except for February, for which he introduced the leap year. Subsequently the emperors Augustus and Constantine the Great slightly amended it.

The solar and the Julian year differ by only a few minutes, but this little discrepancy led to significant errors after enough time passed. Towards the end of the sixteenth century, for instance, the spring equinox fell in early March. In 1582, this anomaly prompted Pope Gregory XIII to issue a papal bull, according to which that year's month of October was shortened by ten days and the day of February 29 was cancelled in the end-of-the-century years, except for years that are multiples of 400 .

But Gleb Nosovski, a close collaborator of Anatoli Fomenko, disagreed with the computations that led to Pope Gregory's changes. He specifically referred to the following passage from the papal bull:

Our care was not only to reinstate the equinox in its long ago nominated place from which it has deviated since the Council of Nicaea by approximately ten days, and to return the 14th Moon [full Moon] to its place, from which it has deviated by four and five days, but also to settle such modes and rules according to which future equinoxes and the 14th Moon would never move off their places. . . . Therefore, to return the equinox to its proper place established by the Church fathers of the Council of Nicaea on the 12th day before the April calends [March 21], we prescribe and order relative to October of the current year, 1582, that ten days, from the third day before nonas [October 5] to the eve of the ides [October 14] inclusive, be deleted.

Nosovski found two errors in this quote. The first has to do with the time difference between the full moon and the spring equinox, an interval the bull wants to keep constant. But this cannot be done, because the cycle of full moons and the date of the equinox shift at different rates. Nosovski concluded that this mistake likely belonged to those who wrote the bull, for no astronomer could have fallen into this trap.

The second mistake, however, proves to be essential, and it relates to the determination of the dates of the spring equinox and the full moon. To understand it, we should mention that Scaliger dated the First Council of Nicaea at AD 325. This year is crucial for the accuracy of the Gregorian reform, because the ten-day correction depends on it. Indeed, the Christian calendar has a rigid and a flexible part. The former is the old-style solar Julian system, with its fixed celebrations, whereas the latter is the lunar Easter Book, which determines the variable feasts and festivals of the Christian church. With no exception, all religious services are based on these two systems.

Tradition claims that the difficulty of combining the lunar and the solar calendars has confronted theologians since the second century $\mathrm{AD}$, when the church first celebrated Easter. The Easter Book, canonized by the First Council of Nicaea in $\mathrm{AD} 325$, provides the rules on which day this celebration should occur. But the dating system in the Easter Book is confusing, since the original text of the Nicaean Creed has not survived. We know how to compute the date of Easter only from the message of Constantine to the bishops who were absent from the council, and this document doesn't ask for Easter to take place after the spring equinox. By about AD 1330, the medieval scholar Matthew Vlastar wrote the following about how to determine the anniversary of Christ's resurrection in the Collection of Rules of the Holy Fathers of the Church:

The rule on Easter has two restrictions: not to celebrate together with the Israelites and to celebrate after the spring equinox. Two more were added by necessity: to have the festival after the very first full Moon after the equinox and not on any day but on the first Sunday after the full Moon. All the restrictions except the last one have been kept firmly until now, but now we often change for a later Sunday. We always count two days after the Passover [full Moon] and then turn to the following Sunday. This happened not by ignorance or inability of the Church fathers who confirmed the rules, but because of the lunar motion.

In Vlastar's time, the last condition of Easter was violated: if the first Sunday took place within two days after the full moon, the celebration of Easter was postponed until the next weekend. This change was necessary because of the difference between the real full moon and the one computed in the Easter Book. The error, of which Vlastar knew, is twenty-four hours in 304 years. Therefore the Easter Book must have been written around AD 722. Had Vlastar been aware of the Easter Book's AD 325 canonization, he would have noticed the three-day gap that had accumulated between the dates of the real and the computed full moon in more than 1,000 years. So he either was unaware of the Easter Book or knew the correct date when it was written, which could not be near AD 325.

Nosovski used Gauss's Easter formula to calculate the Julian dates of all spring full moons from 
the first century AD up to our time and compared them with the Easter dates obtained from the Easter Book. He thus concluded that three of the four conditions imposed by the First Council of Nicaea were violated until 784, whereas Vlastar had noted that "all the restrictions except the last one have been kept firmly until now." Scaliger had no chance of detecting this fault when proposing the year 325 , because in the sixteenth century the full moon calculations for the distant past couldn't be performed with high accuracy.

There is another reason against the validity of AD 325: the 532-year periodicity of the Easter dates. The last cycle started in 1941. The previous ones were 1409 to 1940,877 to 1408 , and 345 to 876. So it appears strange that the council met in AD 325 and started the Easter cycle 20 years later.

Therefore Nosovski thought that the First Council of Nicaea had taken place in $\mathrm{AD} 876$ or 877 , since the latter is the starting year of the first Easter cycle after $\mathrm{AD} 784$, when Nosovski believed the Easter Book was probably compiled. This conclusion also agreed with his full moon calculations, which showed that the computed and the real full moons occurred on the same day only between $\mathrm{AD}$ 700 and 1000. From 1000 on, the real full moons occurred more than a day after the computed ones, whereas before 700 the order was reversed. The years 784 and 877 also matched the traditional claim that about a century had passed between the compilation and the canonization of the Easter Book.

Unfortunately, this conclusion generated no reaction from historians. Nosovski's mathematical reasoning seems plausible, but it would be interesting to know if the historical aspects he invokes hold water.

\section{The Almagest, Probabilities, and the Method of Least Squares}

The moon's acceleration was only one disagreement between Robert Newton and Anatoly Fomenko. They also strongly differed on the Almagest, the most influential astronomy book ever written. Claudius Ptolemy, one of the greatest scientists of antiquity, wrote it in Alexandria during the reign of the Roman emperor Antoninus Pius, traditionally set from AD 138 to 161. Any firm evidence for a different dating of this treatise would affect the chronology of Rome and consequently most ancient history. This opus touches on the main problems of astronomy, from the nature of the universe to lunar and planetary motion, and contains detailed star catalogs and records of eclipses, occultations, and equinoxes, all of which are prone to mathematical dating. The original version of the Almagest has been lost, but in its many translations the work has been in circulation since ancient times.
In The Crime of Claudius Ptolemy [10], a book published in 1977, Robert Newton accused the ancient astronomer of fabricating evidence. Newton argued that many of the coordinates presented in the Almagest as observations are nothing but fraud. Fomenko disagreed, so he took on the task of dating the book.

His first attempt was based on the fact that every star has a proper motion that is unrelated to the apparent one due to precession. The discovery of this phenomenon is attributed to Edmund Halley, who described it at the beginning of the eighteenth century. Ptolemy had also asked if stars moved independently of each other, but he missed the correct answer.

The motion of stars can be detected only by hundreds of years of precise observations of their tangential components. Using the relative positions given in the Almagest and comparing them with the present ones, Fomenko wanted to find out when the book had been written. But that goal was not easy to achieve. One hurdle was the use of Ptolemy's catalog for tracing the motion of some stars. If the catalog's dating was incorrect, the computed speeds of these stars were also wrong. Fomenko had, therefore, to trace the history of those determinations and eliminate from his analysis the stars related to the Almagest. But the most difficult process was to identify the cataloged stars, a problem that had preoccupied many astronomers starting with the sixteenth century.

In ancient and medieval times the shapes of constellations were not standardized, and their description was often vague. Therefore, telling which star from the catalog corresponds to the one we see in the night sky is difficult. Ptolemy provided positions and magnitudes. For bright objects identification is easier because there are few to choose from, but with faint stars, things get complicated: in the Almagest their coordinates, and also their magnitudes, are often incorrect.

Research done on this problem assumed that the observations were made in the second century $\mathrm{AD}$, a fact that influenced the identification of the stars. The outcome changes for different suppositions. This leads to a circular argument. Fortunately, identification is easier for the stars of zodiacal constellations because they have been studied more carefully for astrological purposes and there is more historical information about them. Of the 350 zodiacal stars recorded in the Almagest, Fomenko chose to focus on the very fast ones, with an individual motion of at least one arc second per year, because slower objects could have traveled distances that were less than those resulting from Ptolemy's observational errors. 
Fomenko then applied the method of least squares. He took the distance between the position of a star as recorded in the Almagest and its real position in a given year, as determined by computations. He then summed up the distances for all stars and repeated the procedure for all years within some interval long enough to avoid bias, from $500 \mathrm{BC}$ to AD 1800. Finally, he compared the results and chose the year corresponding to the minimum sum. Estimates for each century pointed out that the only interval in which the errors were smaller than Ptolemy's ten-arc-minute precision was from $\mathrm{AD} 600$ to 1300, with the highest probability around AD 800.

This conclusion depends on several assumptions, and Fomenko checked the reliability of his result. His estimate showed a very small, but nonzero, probability that the Almagest had been written outside this interval. With admissible (but unrealistic) changes in the parameters, the interval could have been extended as far back in time as $\mathrm{AD}$ 350, a date still two centuries after the traditional dating. The good news was that the outcome didn't change when slightly varying the data. To gain more confidence in this procedure, he also tested star catalogs from the sixteenth and seventeenth centuries, as well as some computer-generated ones. The results proved more than satisfactory: he recovered the known dates within a ten-year margin of error.

The Almagest contains other resources, such as occultations and lunar eclipses, phenomena that are prone to independent dating. Fomenko and his collaborators devised methods to check the dates, which then led them to the time when the Almagest was written. The estimates they obtained were consistent with the previous dating of the Almagest to about AD 800 [3], [4].

So far, historians have ignored these studies, which are published in a mathematics journal that has a reasonably good ranking.

\section{Horoscopes}

A horoscope depicts the positions of the sun, the moon, and the planets Mercury, Venus, Mars, Jupiter, and Saturn among the standard twelve zodiacal constellations at a given time. Except for Mercury and Venus, which are never too far from the sun, with a span of three constellations for the former and five for the latter, the other planets may show up anywhere. As a result, there are 3, 732, 480 possible configurations for these celestial bodies. Because of the planets' fast motion, horoscopes change almost daily. They may repeat themselves after hundreds of thousands of years, or as early as within a few decades. The tedious calculations for finding the possible dates of a particular horoscope are easily performed by computers today.
In the 1990s, Fomenko and his collaborators worked on deciphering and dating some Egyptian images, which they interpreted as horoscopes, such as the Denderah stones, the Esna bas-reliefs, the paintings at Athribis, the Petosiris tomb of Dakhla, and the murals found in the burial chambers of the pharaohs Rameses VI and VII. The difficult part was that of finding the correct interpretation of each symbol. Based on these findings, the team obtained mostly dates from the middle ages, results they claimed in support of their shorter chronology.

But these conclusions don't agree with work done in the late 1950s by Otto Neugebauer and Henry Bartlett Van Hoesen, who published a study of some 200 horoscopes, mostly Greek, but also Egyptian and Arabic [8]. All of them occur explicitly, not in symbolic form, so whenever the text is complete, the interpretation is certain. Unlike Fomenko and his team, Neugebauer and Van Hoesen didn't take every horoscope seriously. They found a few impossible configurations, such as one in which Venus opposes the sun, but most are plausible from the astronomical point of view. They also restricted their study to an ancient interval, ignoring possible dates closer to our time. Their results are statistically meaningful: the Greek dates range from $71 \mathrm{BC}$ to $\mathrm{AD} 621$, clustering around $\mathrm{AD} 100$; the Egyptian dates fall between $37 \mathrm{BC}$ and $\mathrm{AD}$ 93; and most of the Arabic dates are from around $\mathrm{AD} 800$. Their book provides the necessary information for further investigations, as there are many more unstudied horoscopes in the papyrological literature, which comprises tens of thousands of texts.

Even if all of Fomenko's solutions were correct, the number of cases he has studied is too small to justify drawing any conclusion from them. Historians can easily dismiss them as irrelevant because of the uncertainty surrounding the interpretations of the symbols. Nevertheless, the study of horoscopes is an important method, whose potential has not been exhausted yet.

\section{Empirical-Statistical Methods}

One of Fomenko's empirical-statistical methods aims to identify various chronicles that seem different but describe the same historical period, even if they appear in different languages, call their characters differently, and use different geographic names. He started from the premises that a person, deity, country, or city can be known by more than one name: Charlemagne is also known as Carol the Great, God as Allah, Finland as Suomi, and Bratislava as Pressburg. It is reasonable to think that lack of communication allowed name variations to be common in the past, so such chronicles are likely to exist. 
Fomenko designed his method as follows. Take two texts describing several historical events that have a relative but not an absolute dating. Collect various data, such as the number of words used to chronicle a period or the number of times a name occurs in a certain interval of time. Then compare the homolog information. If the numbers you obtain are very different, the periods are probably unrelated. If they are close, continue the investigation with the help of various statistical tools. For consistent results, the two chronicles are likely to describe the same events. Tested on specific texts, such as the Russian Supras'l and Nikiforov chronicles, both referring to events occurring in the period AD 850-1256, the method gave similar statistical results.

A related problem is that of ordering several writings that contain many historical characters, some of whom appear in more than one document. For that, divide the texts into generations, i.e., chapters spanning twenty-four to thirty-three years of history. In any given chapter, only names from the past or present show up. Introduce a quantitative measure: compare the occurrence of names from previous generations with those in the investigated chapters and write down the ratios. Since parents are better remembered than grandparents, more distant generations are ideally less frequently mentioned. In the end, order the chronicles so that all mutual frequencies are close to ideal. This principle yielded good results when tested on reliable documents of the past few centuries.

Fomenko applied these methods to the Old and New Testaments. According to tradition, the Bible describes distinct events, except for the well-known overlaps between the four books of Samuel and Kings and the two books of the Chronicles. But Fomenko's conclusion was different. To reach it, he first divided the Scriptures into 218 chapters, one for each generation that occurs from the total of about 2,000 characters. For instance, Genesis was split into seventy-three chapters: Genesis 1-3 (Adam, Eve), Genesis 4:1-4:16 (Cain, Abel), and so on, whereas Exodus formed only one chapter. The Old Testament consisted of parts 1 to 191, and the New Testament consisted of parts 192 to 218. To check the validity of this division, Fomenko tested it on the already-known biblical overlaps and confirmed them easily.

He then ordered all the chapters according to the above principles and concluded that the Old and New Testaments describe interwoven events and are not separated by several centuries, as previously thought. For instance, the Revelation of St. John the Divine, the last book in the Bible, belongs to the New Testament. Placing it anywhere else would look strange at best since everybody is so used to its current position. But Fomenko's frequency analysis suggest that it belongs near the prophecies of the Old Testament. His new ordering moves Revelation into the same period as the books of Isaiah, Jeremiah, Ezekiel, Daniel, Exodus, and Leviticus. Fomenko himself did not find this placement surprising, because St. John's Revelation reminded him of the apocalyptic nature of Daniel's prophecies in the Old Testament.

Can this empirico-statistical analysis change our understanding of the Bible? So far, biblical scholars seem to have ignored Fomenko's conclusions. But it would be good to see studies that either refute these ideas or use them to better understand Christian theology.

\section{The Dating of Maps}

Fomenko also came up with a method for dating maps, in which he used the following assumptions. Once an error is corrected on a map, it does not appear on subsequent maps, and all the accurate features are maintained. So, for a region with a long cartographic history, the fewer the number of mistakes a map contains, the more recent the map. Given a sequence of maps where the dates when they were drawn is unknown, one can order them chronologically by mutually comparing them and finding the changes that occur. Many criteria that involve some mathematics must be taken into account, including the type of map (globe, flat); the kind of projection (conical, cylindrical, azimuthal); orientation; the arrangements of poles, equator, and tropics; the representation of climatic zones; and so on.

This idea is known to historians. Sir Flinders Petrie, the father of modern archeology, used a similar (but nonmathematical) technique at the beginning of the twentieth century, after noticing the stylistic differences between the articles of pottery found in various graves. By charting those changes, he determined the relative chronology of the graves.

Applying this method, Fomenko found that cartography developed very slowly. The maps of the third and fourth centuries AD were simple sketches, very different from what they depicted. Then their quality improved, with the occurrence of the first fairly accurate globes and planar maps appearing in the $1500 \mathrm{~s}$. But in spite of having Earth's main features present in the latter drawings, their proportions were still poor. Several famous maps attracted Fomenko's attention, such as the globe of Crates, from the second century BC, Tabula Peutingeriana, thought to have originated in the time of the Emperor Augustus (27 BC-AD 14), and one attributed to Claudius Ptolemy in the second century AD. Using his method, Fomenko 
concluded that all of them were in fact produced about a millennium later.

Disregarding these conclusions for the moment, the principles of Fomenko's method meet the same standards historians apply when dealing with evolution patterns, as Sir Flinders Petrie did in his analysis of pottery. Moreover, from the mathematical point of view, there is nothing wrong with these techniques; they use the standard tools of mathematical statistics, which nobody questions. Therefore, as in the case of applying empirical statistics to texts, this idea seems worth pursuing. But can these methods withstand criticism on other fronts? The discipline that deals with the interpretation of such data is known as applied statistics, and its experts are aware of its traps, such as failing to ensure that the pool of data is relevant or not assessing how many experiments fail. These issues are overlooked in Fomenko's work.

Although he claims to obtain absolute dates, it is doubtful that he can achieve that without relying on nonmathematical results. As in the case of texts, he might be able to order the charts, but how can he tell if the earliest maps are from the third century BC or the ninth century AD? It appears that, in his haste to support his previous astronomical findings, he jumped to conclusions too early, thus risking making a yet unsettled method look weak.

\section{Scientific Methods}

Starting with the twentieth century, the progress of physics, chemistry, biology, and other branches of science led to several new dating methods, which established themselves, but not without encountering resistance. Some benefit from mathematical support as well. Among them, the best known are the radiocarbon method, dendrochronology, thermoluminescence, fission tracking, and archeomagnetic dating.

From the mathematical point of view, the radiocarbon method uses a simple linear differential equation that describes radioactive decay. It is physically based on the disintegration of carbon-14, a chemical element with a half-life of about 5,370 years that exists in all living organisms. Once an organism dies, the decay of this element starts, and the method provides the time of death by computing the variable ratio between carbon-14 and the element carbon-12, which is stable, remaining constant in time. In living organisms this ratio is about $10^{-12}$.

The radiocarbon method is based on several hypotheses: the concentration of radiocarbon in the atmosphere is constant and hasn't changed throughout history; the proportion of radiocarbon in all living beings is the same as in the atmosphere and independent of location; physical and chemical conditions such as temperature or humidity do not affect the decay of radiocarbon; the dated samples are not contaminated, so the ratio of carbon-14 to carbon-12 is not affected by external factors. These hypotheses were often criticized in the early days of the method, when large errors occurred, mainly because the measuring techniques were not refined enough. But starting with the 1980s, the new accelerator mass spectroscopy technique (which is as different from the original radiocarbon method as digital photography is from film) led to very good measurements that have small approximation errors. The results obtained in this way are often tested with the help of dendrochronology, the science of determining dates from tree rings.

Thermoluminescence is based on the light that is emitted, in addition to the usual glow, when a crystalline material reaches a temperature of about $500^{\circ} \mathrm{C}$. When pottery, which contains minerals (feldspars, calcite, quartz) with high emissions, breaks and the shards are buried, the process of building up this energy starts all over again. The quantity of thermoluminescence found in these fragments indicates their age. Instead of decay, as happens with carbon-14, this process is described by a differential equation that expresses growth.

Fission tracking is based on particle physics. If the atoms of an element prone to fission, like uranium, are trapped inside a crystal structure, the released radiation "scratches" the inside of the structure. An electron microscope can detect the marks, whose number provides the age of the sample, according to probability theory. If the material is manufactured glass, the heating used in the production erases previous traces, allowing an evaluation of when the sample was made.

Finally, archeomagnetic dating establishes the age of objects by comparing their magnetic information with changes in Earth's magnetic field. As with all the other dating methods, the techniques used in this approach are continually improving.

As time progresses, the scientific dating methods have a greater impact on historical research, and someday historians might use them more heavily for a critical assessment of traditional chronology.

\section{Closing Remarks}

At the end of the sixteenth century, when historical chronology became a science, most mathematical methods used to determine ancient and medieval dates were based on celestial mechanics. Things changed in the twentieth century with the introduction of several scientific dating methods. In parallel, some mathematicians tried new approaches, with some degree of success. These methods provide insight into history but don't seem to be taken very seriously if regarded alone. 
Indeed, historians usually take the results of these methods into account only when the conclusions agree with their chronological expectations. In other words, they give priority to traditional chronology over the above scientific and mathematical methods. This attitude is not surprising. After all, they built the traditional chronology with much effort over a significant interval of time. Nevertheless, it is clear that the more distant historical dates go into the past, the less reliable they are. So, next time we hear that Rome was founded in $753 \mathrm{BC}$, we should take the claim with a grain of salt. We may actually never know for sure exactly when that happened, but we need to hope that the ordering of historical events is correct.

The mathematical methods described above are a first step towards providing historians with more than their original chronological tools and help them keep regarding the past critically. But it is a hasty move to jump to conclusions about the correct dating of ancient events without corroborating many pieces of evidence. Mathematics, however, seems to have infiltrated the study of history, as it did so successfully in other disciplines.

After the dust of controversy settles, there is hope that historians, scientists, and mathematicians will together revisit the existing methods and devise new tools, following the same spirit of cooperation that occurs in so many other fields of human endeavor. But we should not expect too much too soon. This is a field in which progress has been slow, and there are no signs that things will take a sudden turn in the near future.

\section{References}

[1] F. DiAcu, The Lost Millennium: History's Timetables under Siege, 2nd ed., Johns Hopkins Univ. Press, 2011.

[2] A. T. FomenKo, The jump of the second derivative of the moon's elongation, Cel. Mech. 25 (1981), 33-40.

[3] A. T. Fomenko, V. V. KALAShnikov, and G. V. NosovSKI, When was Ptolemy's star catalogue in Almagest compiled in reality? Statistical analysis, Acta Appl. Math. 17 (1989), 203-229.

[4] _ , The dating of Ptolemy's Almagest based on the covering of the stars and on lunar eclipses, Acta Appl. Math. 29 (1992), 281-298.

[5] A. GRAFTON, Joseph Scaliger: A Study in the History of Classical Scholarship, vol. 2, Historical Chronology, Clarendon Press, Oxford, 1993.

[6] _ A premature autobiography?, unpublished manuscript, 2002.

[7] D. HAY, Annalists and Historians: Western Historiography from the Eighth to the Eighteenth Centuries, Methuen, London, 1977.

[8] O. Neugebauer and H. B. VAn Hosen, Greek Horoscopes, Amer. Philos. Soc., Philadelphia, 1959.

[9] I. Newton, The Chronology of Ancient Kingdoms Amended, J. Tonson, J. Osborn, and T. Longman, London, 1728.

[10] R. Newton, The Crime of Claudius Ptolemy, Johns Hopkins Univ. Press, 1977.
[11] _ The Moon's Acceleration and Its Physical Origin, Vol. 1, As Deduced from Solar Eclipses, Johns Hopkins Univ. Press, 1979.

[12] _ , The Moon's Acceleration and Its Physical Origin, Vol. 2, As Deduced from General Lunar Observations, Johns Hopkins Univ. Press, 1984.

[13] R. L. REESE, S. M. EveretT, and E. D. CRAUN, The origin of the Julian Period: An application of congruences and the Chinese Remainder Theorem, Amer. J. Phys. 49 (1981), 658-661.

[14] E. M. ReINGOLD and N. Dershowitz, Calendrical Calculations: The Millennium Edition, Cambridge Univ. Press, 2001.

[15] J. RePCHECK, The Man Who Found Time: James Hutton and the Discovery of Earth's Antiquity, Perseus, Cambridge, Mass., 2003.

[16] A. A. ZALYZNIAK, Linguistics according to A. T. Fomenko, Russian Math. Surveys 55 (2000), 369-404. 